\title{
Effect of Monensin Delivery Method on Dry Matter Intake, Body Condition Score, and Metabolic Parameters in Transition Dairy Cows
}

\author{
C. S. Petersson-Wolfe, ${ }^{\star 1}$ K. E. Leslie,${ }^{\star}$ T. Osborne, ${ }^{\star}{ }^{B}$ B. W. McBride, † R. Bagg, $\ddagger$ G. Vessie,‡ \\ P. Dick, $¥$ and T. F. Duffield* \\ *Department of Population Medicine, University of Guelph, Guelph, Ontario, N1G 2W1 \\ †Department of Animal and Poultry Science, University of Guelph, Guelph, Ontario, N1G 2W1 \\ ‡Elanco Animal Health, a Division of Eli Lilly Inc., Research Park Centre, Guelph, Ontario, Canada N1G 4T2
}

\section{ABSTRACT}

An investigation was conducted to compare the effects of the monensin controlled-release capsule, monensin sodium in feed, and a negative control on feed intake and metabolic parameters in a randomized and blinded clinical trial. A total of 136 Holstein cows and heifers were assigned to a negative control group, administered a monensin controlled-release capsule (CRC) or administered $22 \mathrm{mg} / \mathrm{kg}$ of dry matter of monensin sodium in the total mixed ration (premix). Cows were enrolled $3 \mathrm{wk}$ prior to expected calving; at this time monensin treatment began. Cows were located at the Elora Dairy Research Centre (Elora, Ontario, Canada). Blood samples were obtained at enrollment, at $1 \mathrm{wk}$ prior to expected calving date, at calving, and at 1 and 2 wk postpartum. Sera from these samples were analyzed for $\beta$-hydroxybutyrate (BHBA), nonesterified fatty acids, glucose, urea, bilirubin, aspartate aminotransferase activity, insulin, and cortisol. Cows were assigned a body condition score upon enrollment and upon completion of the trial. The dry matter intake was measured for all cows for the entire experimental period $(12.0,11.7$, and $11.3 \mathrm{~kg} / \mathrm{d}$ for control, premix, and CRC groups, respectively). However, no differences in dry matter intake between treatment groups were noted. The interaction of experimental group and sampling time was significant for serum concentration of BHBA and urea. Both monensin delivery methods significantly decreased serum BHBA postpartum. Urea concentrations were increased in the postpartum period compared with the prepartum samples. The CRC group had a significant impact on reducing the loss in body condition over the study period. Serum concentrations of all measured metabolic parameters varied over the peripartum period. Calving season, parity, and body

Received June 27, 2006.

Accepted November 16, 2006.

${ }^{1}$ Corresponding author: cspw@vt.edu condition score at the start of the study period influenced many of the measured metabolic parameters. Key words: monensin, negative energy balance, feed intake, metabolism

\section{INTRODUCTION}

Dairy cattle are at increased risk for metabolic diseases during late pregnancy and early lactation (Gerloff, 2001), also known as the transition period. This time is more precisely noted as the 3 wk prepartum to 3 wk postpartum (Grummer, 1995; Drackley, 1999), during which animals must cope with high energy demands in conjunction with reduced DMI. Previous reports have indicated nearly $80 \%$ of dairy cows will experience a peripartum period of negative energy balance (Sovani et al., 2000). This imbalance often results in the mobilization of body fat as a readily available source of energy (Goff and Horst, 1997; Sovani et al., 2000). The fat mobilization, in conjunction with reduced DMI, results in increased concentrations of serum glucagon, growth hormone, NEFA, BHBA, and liver triglyceride along with decreased levels of circulating serum insulin and glucose (Herbein et al., 1985; Vazquez-Anon et al., 1994). These hormones and metabolites may predispose dairy cows to a range of diseases, including ketosis (Baird, 1982), retained placenta (Dyk et al., 1995), milk fever (Marquardt et al., 1977), displaced abomasum (Van Winden et al., 2003), and reduced reproductive performance (Dohoo and Martin, 1984; Andersson and Emanuelson, 1985).

One potential way to help alleviate negative energy balance may be through the inclusion of ionophores. The feed additive has been used widely in the beef industry since 1977 to control coccidiosis and improve feed efficiency. Ionophores act to alter the rumen microflora through ion transfer across cell membranes. One of the most commonly used ionophores is monensin (Tyler et al., 1992). The carboxylic polyether is produced from a naturally occurring strain of Streptomyces cinnamonensis. Monensin selectively inhibits the growth of 
gram-positive bacteria, resulting in a shift of the rumen microbial population (Bergen and Bates, 1984). It is a carboxylic ionophore that changes the rumen microflora, resulting in a decrease of the microbes that produce acetate and butyrate and increasing the microbes that produce propionate, the gluconeogenic precursor. This is of great importance to transition dairy cows, which have an increase in glucose demand and a decrease in glucose availability. Extensive literature has been published on the efficacy of monensin as a feed additive. The premix form of monensin is added directly to the feed and therefore must be consumed by the cow. It is speculated that the premix may not deliver the same benefits as the monensin controlled-release capsule (CRC) because of the fluctuation in active ingredient consumed if the cow has a decrease in feed intake around the time of calving. Studies have reported monensin premix use to reduce serum BHBA and NEFA concentrations (Sauer et al., 1989; Thomas et al., 1993; Heuer et al., 2001; Vallimont et al., 2001) and to improve glucose availability (Arieli et al., 2001).

The CRC is an intraruminal device containing $32 \mathrm{~g}$ of monensin in a hexaglycerol distearate matrix core (Cameron and Malmo, 1993). The CRC has been designed to deliver $335 \mathrm{mg} / \mathrm{d}$ of monensin sodium for an average of $95 \mathrm{~d}$ (R. Bagg and P. Dick, unpublished observations). Numerous studies have been conducted to evaluate the effects of the monensin CRC on blood metabolites and disease, and all have found favorable results (Abe et al., 1994; Hayes et al., 1996; Stephenson et al., 1997; Beckett et al., 1998; Duffield et al., 1998a,b; Green et al., 1999). Studies have reported a reduction in serum BHBA concentrations (Abe et al., 1994; Stephenson et al., 1997; Duffield et al., 1998a,b; Green et al., 1999), a reduction in serum NEFA levels (Stephenson et al., 1997), an increase in serum glucose concentrations (Green et al., 1999), and a reduction in the incidence of subclinical ketosis (Duffield et al., 1998a,b).

Despite the numerous studies that have compared the monensin CRC or the monensin premix to negative control, no studies have been published to directly compare the delivery methods of monensin on metabolic parameters, DMI, or BCS. In contrast, various outcomes have been measured to examine the effects of monensin CRC or monensin premix. Furthermore, no studies have published the effects of monensin on serum insulin and cortisol levels in the peripartum period. The mechanism by which monensin may affect cortisol is unknown. However, because monensin has shown to lessen the impact that the precipitous peripartum drop in DMI has on circulating metabolites, it is hypothesized that this may in turn reduce the stress associated with this period. Circulating serum cortisol concentration has been chosen as an indicative measure of stress.
Therefore, the objective of the current study was to evaluate the effects of monensin delivery method on metabolic parameters, DMI, and BCS in transition dairy cows.

\section{MATERIALS AND METHODS}

\section{Study Design}

A total of 136 Holstein cows, 59 primiparous and 77 multiparous, owned by the University of Guelph, located at the Elora Dairy Research Centre (Elora, Ontario, Canada), were used for the experiment. Animals were enrolled from September, 2000 through October, 2001. Animals were allowed to be enrolled only once in the study. Upon enrollment, each cow was randomly assigned using a random numbers table to 1 of 3 experimental groups: a monensin CRC group (CRC), a monensin in-feed group (premix), or a negative control group (control). Researchers and Elora Dairy Research Centre barn staff were blinded to the treatment assignments throughout the entire study period. The study period began approximately $3 \mathrm{wk}$ prior to expected calving. The monensin CRC was administered by the herd technician, and the identification on the CRC was recorded. If a cow regurgitated the $\mathrm{CRC}$, the same $\mathrm{CRC}$ was readministered unless there was visible damage to the CRC. If damage was present, a new CRC was administered and the new identification number was recorded. For the premix group, a supplement containing monensin sodium and soy hulls was formulated so that when added to the TMR, the diet would contain a concentration of $22 \mathrm{mg} / \mathrm{kg}$ of monensin on a DM basis. The same amount of carrier without the monensin was added to the nonsupplemented TMR diets. The TMR for the CRC group and the control group were mixed using the same portable TMR mixing unit, and the premix TMR was mixed in a separate unit to avoid monensin carryover to the other diet. The mixer was validated to ensure that the desired concentration of monensin was achieved, and the premix supplement containing monensin was monitored to ensure the correct concentration of monensin was maintained throughout the trial.

Upon enrollment and completion of the study period each animal was assessed for BCS using a scale of 1 to 5 in quarter-point increments (Edmonson et al., 1989). Blood samples were collected from the coccygeal vein using 10-mL Vacutainer tubes (Becton-Dickinson Vacutainer Systems, Franklin Lakes, NJ) at enrollment, 1 wk prior to expected calving date, on the day of calving, and at 1 and 2 wk postpartum. Collection occurred in the morning at approximately the same time each day. 
Table 1. Diet ingredients (as-fed) and approximate chemical composition (\% DM) for TMR for prepartum Holstein cows

\begin{tabular}{lr}
\hline Ingredient (\% as-fed) & \\
\hline Dry hay & 2.9 \\
Haylage & 16.0 \\
Mineral/salt & 0.6 \\
Soybean meal & 2.1 \\
Corn silage & 75.4 \\
Protein supplement ${ }^{1}$ & 2.1 \\
Chemical & \\
DM (\%) & 48.7 \\
CP (\% of DM) & 15.6 \\
ADF (\% of DM) & 26.5 \\
NDF (\% of DM) & 41.1 \\
Calcium (\% of DM) & 0.8 \\
Phosphorus (\% of DM) & 0.5 \\
$\mathrm{NE}_{\mathrm{L}}$ (Mcal/kg) & 1.5 \\
\hline
\end{tabular}

${ }^{1}$ Protein supplement was formulated and supplied by Floradale Feed Mill (Floradale, Ontario, Canada) $31.2 \%$ CP, $14.9 \%$ soluble protein, $5.9 \% \mathrm{NDF}, 19.2 \% \mathrm{NFC}, 3.2 \%$ fat, $6.3 \% \mathrm{Ca}, 0.4 \% \mathrm{P}, 1.1 \mathrm{Mcal} / \mathrm{kg}$ of $\mathrm{NE}_{\mathrm{L}}$.

\section{Feeds and DMI Determination}

All study animals were fed a TMR ad libitum in individual, partitioned tie stalls. Feed was delivered once daily throughout the entire trial period. Upon enrollment, study animals were fed a TMR formulated for close-up dry cows. Immediately postpartum, all animals were switched to a lactating cow TMR. Diet information is included in Tables 1 and 2.

Samples of the dry cow and lactating cow diets were collected 3 times weekly and frozen until DM analysis took place. Additionally, leftover feed was sampled 3 times weekly, each the day following collection of the diet. Feed samples were pooled together to calculate a weekly average for DM content. The leftover feed samples were weighted based on actual daily intake and pooled to determine the DM content. Following drying

Table 2. Diet ingredients (as-fed) and approximate chemical composition (\% DM) for TMR for lactating Holstein cows

\begin{tabular}{lr}
\hline Ingredient (\% as-fed) & \\
\hline Dry hay & 4.9 \\
Haylage & 17.8 \\
High moisture corn & 11.2 \\
Corn silage & 55.6 \\
Supplement & 10.5 \\
Chemical & \\
DM (\%) & 44.2 \\
CP (\% of DM) & 21.4 \\
ADF (\% of DM) & 22.2 \\
NDF (\% of DM) & 35.8 \\
Calcium (\% of DM) & 1.0 \\
Phosphorus (\% of DM) & 0.5 \\
NE $($ Mcal/kg) & 1.7 \\
\hline
\end{tabular}

\footnotetext{
${ }^{1}$ Supplement was formulated and supplied by Floradale Feed Mill (Floradale, Ontario, Canada) $35.6 \% \mathrm{CP}, 18.5 \%$ soluble protein, $23.1 \%$ $\mathrm{NDF}, 22.4 \% \mathrm{NFC}, 3.8 \%$ fat, $2.6 \% \mathrm{Ca}, 1.1 \% \mathrm{P}, 1.4 \mathrm{Mcal} / \mathrm{kg}$ of $\mathrm{NE}_{\mathrm{L}}$.
}

$\left(60^{\circ} \mathrm{C}, 48 \mathrm{~h}\right)$, the samples were weighed to determine the moisture loss and DMI was calculated. The DMI was calculated daily based on the consumed feed and the DM of feed and the leftover feed. Weekly DMI averages were calculated from the daily intakes for each cow.

\section{Sample Handling and Laboratory Procedures}

Blood samples were refrigerated $\left(4^{\circ} \mathrm{C}\right)$ after collection. Within 12-h postcollection, serum was separated from samples by centrifugation $(700 \times g, 15 \mathrm{~min})$, and transferred into tubes for storage $\left(-20^{\circ} \mathrm{C}\right)$ without preservative. One aliquot of serum was submitted to the Animal Health Laboratory (Department of Pathobiology, University of Guelph, Guelph, Ontario) for determination of BHBA, NEFA, glucose, bilirubin, and urea concentrations and for aspartate aminotransferase (AST) activity. All tests were conducted on a Hitachi 911 automated analyzer (Roche, Laval, Quebec, Canada). Reagents for all metabolic items were supplied by Roche with the exception of BHBA (Sigma, Oakville, Ontario, Canada) and NEFA (Randox, Mississauga, Ontario, Canada).

Standard RIA methods were used to determine the serum concentration of insulin (kit TKINX) and cortisol (kit TKCO5) for each sample (Coat-A-Count, Diagnostic Products, Intermedico, Toronto, Ontario, Canada). Test sera were added in duplicates to the hormone-specific antibody-coated kit tubes in $200-\mu \mathrm{L}$ aliquots for insulin and $100-\mu \mathrm{L}$ aliquots for cortisol. To determine insulin concentration, samples were incubated $\left(22^{\circ} \mathrm{C}\right.$, overnight), and count per minute was recorded immediately following aspiration. For cortisol concentration, samples were incubated in a water bath $\left(37^{\circ} \mathrm{C}, 45 \mathrm{~m}\right)$ prior to aspiration. Immediately following aspiration, counts per minute were recorded. To ensure quality, duplicates with a coefficient of variation of $\leq 10 \%$ were considered valid.

\section{Data Management and Statistical Analysis}

Descriptive statistics were derived using the frequency procedure in SAS (The SAS System for Windows Version 8.2, Cary, NC). The analysis of the serum metabolic profile, BCS at the end of the study period, and DMI was performed using the PROC MIXED model procedure in SAS (The SAS System for Windows, Version 8). A repeated measures approach was used for the DMI and serum metabolic profile analyses. The appropriate error structure was assessed and used for each outcome variable. All outcome variables were evaluated for normality. A logarithmic transformation was applied to data that were not normally distributed. 
Table 3. Results of statistical analyses for serum metabolites and the change in BCS over the study period in Holstein cows treated with a monensin controlled-release capsule (CRC) $3 \mathrm{wk}$ prior to calving, monensin inclusion in the diet at $22 \mathrm{mg} / \mathrm{kg}$, or served as negative controls using PROC MIXED in SAS (SAS Inst. Inc., Cary, NC)

\begin{tabular}{lcccccc}
\hline $\begin{array}{l}\text { Dependent } \\
\text { variable }\end{array}$ & $\begin{array}{c}\text { Experimental } \\
\text { group }\end{array}$ & $\begin{array}{c}\text { Sample } \\
\text { time }\end{array}$ & $\begin{array}{c}\text { Calving } \\
\text { season }\end{array}$ & Parity & $\begin{array}{c}\text { BCS at } \\
\text { start }\end{array}$ & Interaction $^{1}$ \\
\hline Log BHBA & 0.01 & $<0.0001$ & 0.002 & 0.04 & $\mathrm{NS}^{2}$ & 0.03 \\
Log NEFA & 0.48 & $<0.0001$ & $\mathrm{NS}$ & $<0.0001$ & 0.02 & NS \\
Log AST & 0.16 & $<0.0001$ & $\mathrm{NS}$ & 0.002 & $\mathrm{NS}$ & $\mathrm{NS}$ \\
Glucose & 0.38 & $<0.0001$ & $<0.0001$ & $<0.0001$ & $\mathrm{NS}$ & $\mathrm{NS}$ \\
Urea & 0.07 & $<0.0001$ & $\mathrm{NS}$ & $<0.0001$ & $\mathrm{NS}$ & 0.03 \\
Log bilirubin & 0.60 & $<0.0001$ & $\mathrm{NS}$ & $<0.0001$ & $\mathrm{NS}$ & $\mathrm{NS}$ \\
Log insulin & 0.12 & $<0.0001$ & $<0.0001$ & $\mathrm{NS}$ & $\mathrm{NS}$ & $\mathrm{NS}$ \\
Log cortisol & 0.55 & $<0.0001$ & 0.05 & $\mathrm{NS}$ & $\mathrm{NS}$ & $\mathrm{NS}$ \\
BCS & $<0.0001$ & $\mathrm{NA}^{4}$ & $<0.0001$ & $\mathrm{NS}$ & $<0.0001$ & $\mathrm{NA}$ \\
\hline
\end{tabular}

${ }^{1}$ Interaction of experimental group $\times$ sample time.

${ }^{2}$ Not significant $(P>0.05)$.

${ }^{3}$ Aspartate aminotransferase activity.

${ }^{4}$ Not applicable.

Other cow-level variables were offered into the model included parity, calving season, and BCS at enrollment. Experimental group was forced into each model. Season was classified as winter, December to February; spring, March to May; summer, June to August; and fall, September to November. All variables were offered into the model and were removed by backward elimination. All biologically plausible 2-way interaction terms were tested for significance. For each model, least squares means and standard errors were determined for significant variables. To adjust for multiple comparisons within each model, Tukey's adjusted $P$-values were calculated for each variable. Once the final model was chosen, the residuals were checked for homoscedasticity, outliers, leverage cases, and normal distribution. Significance was considered at $P \leq 0.05$.

\section{RESULTS}

A total of 45,46 , and 45 cows were enrolled in the control group, monensin CRC, and monensin premix groups, respectively. First-lactation animals repre-

Table 4. Results of statistical analyses for log serum BHBA concentrations in Holstein cows treated with a monensin controlled-release capsule (CRC) $3 \mathrm{wk}$ prior to calving, monensin inclusion in the diet at $22 \mathrm{mg} / \mathrm{kg}$, or served as negative controls using PROC MIXED in SAS (SAS Inst. Inc., Cary, NC)

\begin{tabular}{lccc}
\hline Variable & Estimate & SE & $\begin{array}{c}\text { Adjusted } \\
P \text {-value }\end{array}$ \\
\hline Intercept & 6.49 & 0.09 & $<0.0001$ \\
Experimental group $\times$ sampling time & $\mathrm{NA}^{1}$ & $\mathrm{NA}$ & 0.03 \\
Season & & & \\
$\quad$ Winter vs. fall & 0.21 & 0.06 & $<0.01$ \\
Summer vs. fall & 0.13 & 0.05 & 0.03 \\
\hline
\end{tabular}

${ }^{1}$ Not applicable. sented $44 \%$ of the study population, compared with $29 \%$ in their second lactation, and $27 \%$ in their third or greater lactation. Serum concentrations of BHBA, NEFA, bilirubin, insulin, and cortisol and AST activity were skewed. Therefore, a logarithmic transformation was performed on each of these dependent variables, which resulted in a normal distribution. The unstructured error structure was used for all metabolites except serum cortisol concentration, in which spatial power was used. Significance of independent variables offered into each metabolite model is shown in Table 3.

The final model for serum BHBA concentration was based on complete records from 133 cows (Table 4). A total of 3 animals were missing results from at least 1 of the 5 serum BHBA concentrations and therefore were removed from the analysis. The interaction of experimental group and sampling time was significant for BHBA concentration (Figure 1). Additionally, animals calving in the winter and summer had significantly higher serum BHBA concentrations (818.37 \pm 38.22 $\mu \mathrm{mol} / \mathrm{L}$ and $815.89 \pm 42.76 \mu \mathrm{mol} / \mathrm{L}$, respectively) compared with fall calvings $(746.76 \pm 40.75 \mu \mathrm{mol} / \mathrm{L})$.

A model was fit for serum urea concentration based on complete records from 136 cows (Table 5). The interaction of experimental group and sampling time was significant for urea concentration (Figure 2). Serum urea concentrations were lower prepartum than postpartum and peaked at calving. In addition, primiparous animals had significantly lower serum urea concentrations $(3.91 \pm 0.06 \mathrm{mmol} / \mathrm{L})$ when compared with multiparous animals $(4.42 \pm 0.08 \mathrm{mmol} / \mathrm{L})$.

No significant treatment effects were found for serum NEFA, AST, glucose, or bilirubin. All of these serum parameters changed over time and were influenced by parity. Glucose showed some seasonal influence, with 
Table 5. Results of statistical analyses for serum urea concentrations in Holstein cows treated with a monensin controlled-release capsule (CRC) $3 \mathrm{wk}$ prior to calving, monensin inclusion in the diet at $22 \mathrm{mg} /$ $\mathrm{kg}$, or served as negative controls using PROC MIXED in SAS (SAS Inst. Inc., Cary, NC)

\begin{tabular}{lccc}
\hline Variable & Estimate & $\mathrm{SE}$ & $\begin{array}{c}\text { Adjusted } \\
P \text {-value }\end{array}$ \\
\hline Intercept & 5.17 & 0.43 & $<0.0001$ \\
Experimental group $\times$ sampling time & $\mathrm{NA}^{1}$ & $\mathrm{NA}$ & 0.03 \\
Parity & & & \\
$\quad$ First lactation vs. second lactation & -0.63 & 0.11 & $<0.0001$ \\
First lactation vs. third or greater lactation & -0.52 & 0.11 & $<0.0001$ \\
\hline
\end{tabular}

${ }^{1}$ Not applicable.

highest glucose values occurring in cows that calved in fall and winter $(3.06 \pm 0.09 \mathrm{mmol} / \mathrm{L})$ and lowest for those that calved in the spring and summer $(2.56 \pm 0.11$ $\mathrm{mmol} / \mathrm{L})$.

The final model for serum insulin concentration was based on complete records from 127 cows. A total of 9 animals were missing results from at least 1 of the 5 serum insulin concentrations and therefore were removed from the analysis. Experimental group did not significantly affect serum insulin concentration, nor did the interaction between sample time and group. An effect of season showed that serum concentrations of insulin were lowest in the summer $(4.94 \pm 0.37 \mu \mathrm{IU} /$ $\mathrm{mL})$ as compared with fall $(5.90 \pm 0.32 \mu \mathrm{IU} / \mathrm{mL})$, winter $(7.80 \pm 0.49 \mu \mathrm{IU} / \mathrm{mL})$, and spring $(9.77 \pm 0.86 \mu \mathrm{IU} / \mathrm{mL})$. Additionally, the serum concentration of insulin varied over time. The highest concentrations were seen at enrollment $(10.38 \pm 0.68 \mu \mathrm{IU} / \mathrm{mL})$ compared with all other sampling times. Additionally, serum insulin concentration was significantly higher $1 \mathrm{wk}$ prepartum (6.49 \pm

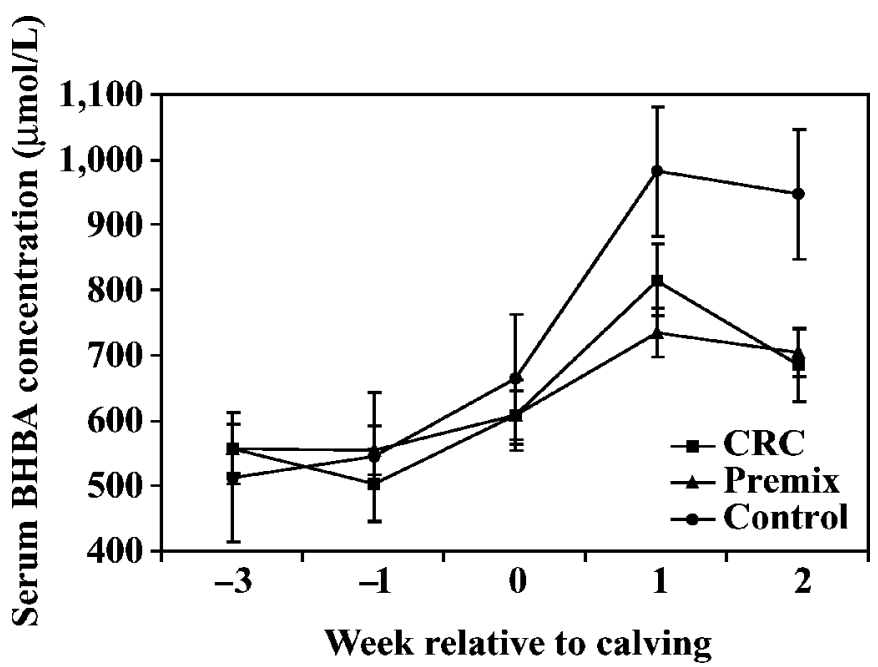

Figure 1. Least squares mean values for serum BHBA concentrations before and after calving in Holstein cows treated with a monensin controlled-release capsule (CRC) 3 wk prior to calving, fed monensin in the diet at $22 \mathrm{mg} / \mathrm{kg}$, or served as negative controls.
$0.37 \mu \mathrm{IU} / \mathrm{mL})$ compared with calving $(6.16 \pm 0.58 \mu \mathrm{IU} /$ $\mathrm{mL}$ ) as well as the 2 postpartum samples (wk $1=4.88$ $\pm 0.38 \mu \mathrm{IU} / \mathrm{mL}$; wk $2=4.84 \pm 0.34 \mu \mathrm{IU} / \mathrm{mL})$. Monensintreated animals, both CRC and premix, had numerically higher serum insulin concentrations at calving compared with negative controls. However, this difference was not significant. In the final model there were 16 potential outliers with low serum insulin concentrations. However, the majority of these observations were from the control group during the summer season and from animals in their first or second lactation. These observations were not normally distributed among experimental groups, and it was agreed that these results might be an effect of experimental group and not actual outliers. Therefore, these observations were left in the final model.

A model was fit to examine the effects of experimental group on serum cortisol concentrations based on complete records from 129 cows. A total of 7 cows were missing serum cortisol concentration results from at

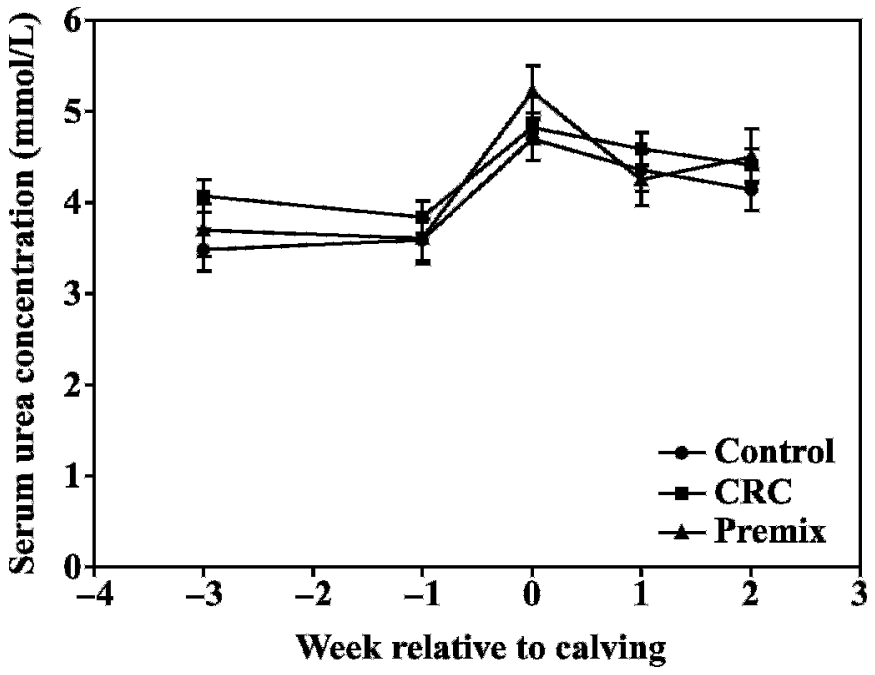

Figure 2. Least squares mean values for serum urea concentrations before and after calving in Holstein cows treated with a monensin controlled-release capsule (CRC) 3 wk prior to calving, fed monensin in the diet at $22 \mathrm{mg} / \mathrm{kg}$, or served as negative controls. 


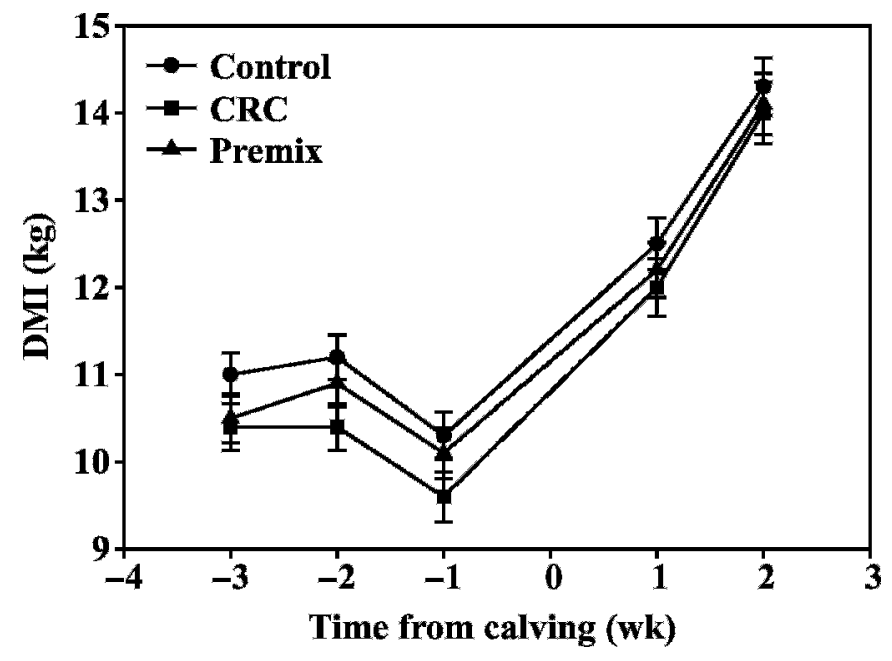

Figure 3. Average DMI (kg) before and after calving in Holstein cows that were treated with a monensin controlled-release capsule (CRC) 3 wk prior to calving, fed monensin in the diet at $22 \mathrm{ppm}$, or served as negative controls.

least 1 of the 5 samples and therefore were removed from the analysis. Experimental group did not significantly affect serum cortisol concentration nor did the interaction between sample time and group. A seasonal effect showed animals calving in the spring (10.46 \pm $1.27 \mathrm{ng} / \mathrm{mL}$ ) had significantly higher serum cortisol concentrations compared with fall calvings $(7.09 \pm 0.47 \mathrm{ng} /$ $\mathrm{mL}$ ). Additionally, serum cortisol concentrations significantly differed between sampling times. Cortisol concentrations began to rise $1 \mathrm{wk}$ prepartum $(8.05 \pm$ $0.53 \mathrm{ng} / \mathrm{mL})$, peaked at calving $(16.60 \pm 1.24 \mathrm{ng} / \mathrm{mL})$, and by 1 wk postpartum $(5.12 \pm 0.45 \mathrm{ng} / \mathrm{mL})$ had returned to levels lower than 3 wk prepartum (5.00 \pm 0.34 $\mathrm{ng} / \mathrm{mL}$ ).

The final model used to analyze BCS at the end of the study was based on 136 observations and is shown in Table 6. The BCS at enrollment was a significant,

Table 6. Results of statistical analyses for body condition score of Holstein cows treated with a monensin controlled-release capsule (CRC) $3 \mathrm{wk}$ prior to calving, monensin inclusion in the diet at $22 \mathrm{mg} /$ $\mathrm{kg}$, or served as negative controls at the end of the study period using PROC MIXED in SAS (SAS Inst. Inc. Cary, NC)

\begin{tabular}{lccc}
\hline Variable & Estimate & SE & $\begin{array}{c}\text { Adjusted } \\
P \text {-value }\end{array}$ \\
\hline Intercept & 1.53 & 0.09 & $<0.0001$ \\
Experimental group & & & \\
$\quad$ Control vs. CRC & -0.12 & 0.02 & $<0.0001$ \\
CRC vs. premix & 0.11 & 0.03 & 0.0001 \\
BCS at enrollment & 0.44 & 0.03 & $<0.0001$ \\
Season & & & \\
$\quad$ Winter vs. fall & -0.10 & 0.03 & $<0.01$ \\
$\quad$ Spring vs. fall & -0.18 & 0.03 & $<0.0001$ \\
Summer vs. fall & -0.14 & 0.03 & $<0.0001$ \\
\hline
\end{tabular}

positive predictor for BCS at the end of the study. Additionally, experimental group significantly affected the final BCS. Animals that served as the negative control and those fed monensin had a significantly lower BCS at the end of the study (BCS $3.03 \pm 0.02$ ) compared with those administered a monensin CRC (BCS $3.14 \pm 0.02$ ). Furthermore, a seasonal effect showed animals calving in winter, spring, and summer had a significantly lower BCS (3.12 $\pm 0.03,3.00 \pm 0.03$, and $2.98 \pm 0.02$, respectively) compared with fall calvings $(3.14 \pm 0.02)$.

A model of DMI included parity and week, which both significantly influenced intake (Figure 3). Treatment tended to influence intake $(P=0.09)$ with the corresponding least squares means for DMI 12.0, 11.3, and $11.7 \mathrm{~kg} / \mathrm{d}$ for control, CRC, and premix respectively. Using a Tukey-adjusted $P$-value, CRC-treated cows tended $(P=0.07)$ to have lower DMI than control cows. Cows receiving premix were not different from CRC or control cows. There was no interaction of treatment $\times$ week.

\section{DISCUSSION}

The objective of the current study was to evaluate the effects of monensin CRC, monensin inclusion in the TMR and a negative control group on serum metabolites, BCS, and DMI over a 5 -wk peripartum period. The administration of a monensin CRC or supplementation with monensin premix to transition dairy cow $3 \mathrm{wk}$ before the expected calving date significantly reduced serum BHBA concentrations in early lactation when compared with control cows. These results are consistent with previously published work using the CRC (Duffield et al., 1998b). However, there is no published work comparing the 2 administration methods of monensin.

In the first and second week postpartum, the CRC reduced BHBA concentrations by 17 and 28\%, respectively. This is consistent with work done by Duffield et al. (1998b), showing treatment with monensin CRC reduced BHBA concentrations in the first 3 wk following calving by $20 \%$. Green et al. (1999) also reported a reduction in serum BHBA concentrations but the reduction in BHBA was more substantial than in the current study. Multiparous $(n=41)$ and primiparous $(n=11)$ animals showed a 35 and $27 \%$ reduction, respectively, in serum BHBA concentration for 6 wk postpartum compared with a placebo CRC group (Green et al., 1999). The earlier study involved considerably fewer animals; however, both studies were done within the same research herd. The most likely explanation for the differed effect on BHBA is that in the study by Green et al. (1999) a feed restriction model was used to induce subclinical ketosis. It is hypothesized that 
experimentally reducing DMI may result in a more pronounced increase in BHBA concentrations and lead to larger differences for monensin-supplemented compared with control animals. The study by Duffield et al. (1998b) involved considerably more cows than the current study and was performed in several different herds with several different management practices. Therefore such a large-scale trial may give a more appropriate estimate of the reduction in BHBA concentrations to be expected in a field situation with the monensin CRC.

The serum BHBA concentrations for animals receiving the monensin premix were also significantly reduced. The BHBA concentration was reduced by $25 \%$ in the first week postpartum and by $26 \%$ in the second week postpartum. This is consistent with previously published work. Heuer et al. (2001) reported treatment with monensin premix significantly lowered serum BHBA concentrations when monensin was added to the diet at 2 wk prior to expected calving date. In the current study, treatment began 3 wk prior to expected calving date. Heuer et al. (2001) combined 3 dosages of monensin topdress $(150,300,450 \mathrm{mg} / \mathrm{cow}$ per d) into 1 treatment effect and did not indicate a percent reduction in BHBA concentration. However, the study did indicate the reduction was significant and involved a large number of animals. An earlier study examined various feeding rates of monensin (Sauer et al., 1989). Results indicated animals fed monensin premix $(30 \mathrm{mg} /$ $\mathrm{kg}$ ) had significantly decreased BHBA concentrations (45\%). Additionally, the incidence of subclinical ketosis was reduced $42 \%$. The low monensin group $(15 \mathrm{mg} / \mathrm{kg})$ showed a numeric reduction in BHBA concentrations, but the difference was not significant when compared with the control cows (Sauer et al., 1989).

The reduction in BHBA concentrations in the current study is consistent with the mechanism of action of monensin. It is known that monensin increases the production of propionate and decreases the concentrations of butyrate in the rumen (Richardson et al., 1976). The decrease in BHBA could be related to the decrease in butyrate, which is converted to BHBA in the rumen epithelium. This reduction could also be explained when considering the increase in the production of propionate. Propionate is a precursor for gluconeogenesis. The increase in the production of propionate would result in an increase in glucose production. This increase in glucose would result in a decrease in production of ketone bodies, which are mainly produced when the demand for glucose is greater than the supply.

Although there were no significant differences in serum glucose concentrations found in either of the treatment groups, both treatment groups had numerically higher serum glucose levels than the control group. The results of the current study are not in agreement with work done by Duffield et al. (1998b), in which significantly higher glucose levels were found in cows treated with a monensin CRC. The increase in the current study was $0.13 \mathrm{mmol} / \mathrm{L}$ for the CRC group and $0.11 \mathrm{mmol} / \mathrm{L}$ for the premix group. Duffield et al. (1998b) reported a 0.16 and $0.22 \mathrm{mmol} / \mathrm{L}$ increase in glucose concentrations in wk 1 and 2 postpartum, respectively.

Several other studies (Thomas et al., 1993; Abe et al., 1994; Green et al., 1999) have reported treatment with monensin did not significantly increase serum glucose concentrations. Abe et al. (1994) reported a numeric, but not significant, increase of approximately $0.2 \mathrm{mmol} / \mathrm{L}$ in the first week postpartum. The lack of significance could be attributed to the small sample size and wide variation. Green et al. (1999) reported an average increase of $0.14 \mathrm{mmol} / \mathrm{L}$ in the 6 wk postpartum. Work done by Duffield et al. (1998b) was better able to detect significant differences in glucose concentrations. This detectable difference was likely due to a substantially larger study population and therefore greater power to detect small differences.

The current study found a significant interaction between circulating serum urea concentration and sample time. Postpartum urea concentrations were higher for all experimental groups, including the negative control, compared with the prepartum samples. Serum urea concentrations were highest at calving for each of the experimental groups, with the premix group being numerically the highest. However, this difference was not significant. Consistent with previous work, Abe et al. (1994) reported no difference in urea concentrations between monensin CRC-treated cows and controls. However, in contrast with the current study, Abe et al. (1994) also reported no changes in serum urea concentrations over time. The design of the current study and that reported by Abe et al. (1994) were considerably different and may contribute to conflicting results. For the current study, animals were fed a TMR. In the study by Abe et al. (1994), trial animals were fed on pasture consisting of different grasses and supplemented once daily with $3 \mathrm{~kg}$ of dairy pellets.

Although experimental group did not have a significant impact on serum urea concentrations on the current study, Duffield et al. (1998b) reported monensin CRC treatment significantly increased serum urea concentrations in wk 2 and 3 postpartum. Similarly to Duffield et al. (1998b), Hayes et al. (1996) found an increase in serum urea concentrations in the first month postpartum for cows treated with a monensin CRC. The biology behind a potential influence of monensin on serum urea has previously been suggested to be related to an increase in bypass protein reaching the small intestine and a greater supply of absorbed AA 
for liver metabolism, resulting in an increase in deamination to urea (Plaizier et al., 2000). If this hypothesis is true, there are likely dietary protein interactions with monensin that could explain differences between studies. An alternative hypothesis is that monensin may improve liver function in early lactation through beneficial effects on liver metabolism, and thus enhance the ability of the liver to make urea.

Experimental group did not significantly affect serum insulin concentrations. However, concentrations were higher prepartum than in the postpartum period. Due to the inherent drop in DMI immediately prepartum, and the high energy demand in early lactation, a negative effect on serum insulin concentration has been shown (Hayirli et al., 2002; Holtenius et al., 2003). This is consistent with results from the current study.

The heat stress associated with the warmer summer temperatures can cause reduced DMI, regardless of DIM. This drop in energy intake has repercussions similar to the characteristic peripartum drop, including body fat mobilization resulting in NEFA and BHBA production. The decline in DMI subsequently affects circulating serum insulin concentration. A seasonal effect was shown in the current study. Animals calving in the summer had the lowest serum insulin concentration compared with all other calving seasons. These results are similar to previous work, which showed serum BHBA concentrations increased during the spring and summer months (Duffield et al., 1998a).

Monensin alters energy metabolism (Stephenson et al., 1997) and has the potential to improve the health of dairy cows. In some previous studies a measured increase in glucose by monensin might have also resulted in a corresponding increase in serum insulin, had it been measured. However, in the current study, animals treated with monensin, as a feed additive or from a CRC, had serum insulin concentrations that were not different from the control group. The simplest explanation of this finding is that there was also no effect of monensin on serum glucose in this study.

Serum and plasma cortisol concentrations increase at parturition (Guidry et al., 1976; Schwalm and Tucker, 1978; Horst and Jorgensen, 1982; Patel et al., 1996; Tucker, 2000; Preisler et al., 2000), likely due to the stress associated with calving (Tucker, 2000) and typically return to basal levels within 1 wk postpartum (Guidry et al., 1976, Schwalm and Tucker, 1978; Horst and Jorgensen, 1982; Patel et al., 1996; Preisler et al., 2000). This short spike is consistent with results from the current study. However, no differences were seen between experimental groups.

At the end of the study period, the average BCS was significantly higher in animals treated with a monensin CRC compared with both the monensin premix and negative control groups. These results are consistent with previous work. Duffield et al. (1998b) reported a significant increase in BCS for monensin CRC treated animals compared with control animals. Research with the monensin premix has shown no significant increase in BCS compared with control (Sauer et al., 1989). These results suggest cows administered a monensin CRC lose less body condition after calving.

In the current study DMI was lower for cows receiving a monensin CRC treatment compared with cows serving as controls $(P=0.07)$. However cows receiving a diet with monensin in feed had DMI that was not different from control or CRC. The impact of monensin on DMI in dairy cattle is inconsistent in the literature. Some of these differences may be related to stage of lactation and also statistical power. The work by Sauer et al. (1989) reported a decrease in DMI in cows treated with 33 ppm of monensin during early lactation. Wagner et al. (1999) also showed decreased DMI during the whole lactation period at 16 and 24 ppm; however, only the $24 \mathrm{ppm}$ dose affected DMI precalving. Many studies involving the CRC have been larger, extensive field studies, and have not therefore measured DMI. Green et al. (1999) and Abe et al. (1994) have reported no significant impact of monensin delivered with the CRC on DMI in dairy cows in the transition period. The mode of action of depressed DMI with monensin supplementation may be mediated through increased propionate supply and glucose demand by the mammary gland (Oba and Allen, 2003). Oba and Allen (2003) have proposed that greater glucose demand increases gluconeogenesis and reduces propionate oxidation in the liver, thereby minimizing the impact of propionate on reducing DMI. One would therefore expect less impact of monensin on DMI in early lactation, given the glucose demand during that stage of lactation. In the current study, the tendency for reduced intake in the monensin CRC group appears to be occurring primarily in the precalving time period (Figure 1).

Although there are similarities in the efficacy of the $\mathrm{CRC}$ and the feed-delivered monensin reported in the current study, it is important to note that the feeddelivered monensin used in this study was fed under optimal conditions at a research farm in a controlled setting. The animals on this study did not have to compete for feed and feed was provided on an ad libitum basis. It is possible that in a field situation, a CRC may have advantages over feed-delivered monensin because of the continual release, which provides a constant daily dosage of $335 \mathrm{mg} / \mathrm{d}$ during a time when the DMI is very inconsistent. However, in the current study both monensin treatments were efficacious in reducing BHBA concentrations. Based on the DMI, monensin dose in the premix group averaged $257 \mathrm{mg} / \mathrm{cow}$ per $\mathrm{d}$ 
during the experimental period. The higher daily dose of the CRC might explain the reduced BCS loss found for that group, indicating reduced fat metabolism.

This is the first study to directly compare the 2 methods of delivery of monensin. Previous work has shown that the CRC consistently reduces the risk of subclinical ketosis and energy associated disease. The efficacy of feed-delivered Rumensin on cow health requires further research.

\section{CONCLUSIONS}

The administration of a monensin CRC or the inclusion of monensin premix in the diet of early lactation dairy cows significantly reduced serum concentrations of BHBA. The monensin CRC significantly decreased the loss of body condition after calving. Further studies need to be conducted to confirm the findings of the current study with regard to the differences noted between the monensin CRC and the monensin premix. The monensin CRC and the monensin premix appear to be useful aids for reducing serum ketone concentrations in early lactation.

\section{ACKNOWLEDGMENTS}

The authors thank Angela Fairfield, and Jeromy TenHag for technical assistance. Elanco Animal Health, the Dairy Farmers of Ontario, and the Ontario Ministry of Food and Agriculture are gratefully acknowledged for financial support.

\section{REFERENCES}

Abe, N., I. J. Lean, A. Rabiee, J. Porter, and C. Graham. 1994. Effects of sodium monensin on reproductive performance of dairy cattle. II. Effects on metabolites in plasma, resumption of ovarian cyclicity and oestrus in lactating cows. Aust. Vet. J. 71:277-282.

Andersson, L., and U. Emanuelson. 1985. An epidemiological study of hyperketonaemia in Swedish dairy cows: Determinants and the relation to fertility. Prev. Vet. Med. 3:449-462.

Arieli, A., J. E. Vallimont, Y. Aharoni, and G. A. Varga. 2001. Monensin and growth hormone effects on glucose metabolism in the prepartum cow. J. Dairy Sci. 84:2770-2776.

Baird, G. D. 1982. Primary ketosis in the high-producing dairy cow: Clinical and subclinical disorders, treatment, prevention and outlook. J. Dairy Sci. 65:1-10.

Beckett, S., I. Lean, R. Dyson, W. Tranter, and L. Wade. 1998. Effects of monensin on reproduction, health, and milk production of dairy cows. J. Dairy Sci. 81:1563-1573.

Bergen, W. G., and D. B. Bates. 1984. Ionophores: Their effect on production efficiency and mode of action. J. Anim. Sci. 58:1528-1539.

Cameron, A. R., and J. Malmo. 1993. A survey of the efficacy of sustained-release monensin capsules in the control of bloat in dairy cattle. Aust. Vet. J. 70:1-4.

Dohoo, I. R., and S. W. Martin. 1984. Subclinical ketosis: Prevalence and associations with production and disease. Can. J. Comp. Med. $48: 1-5$.

Drackley, J. K. 1999. Biology of dairy cows during the transition period: The final frontier? J. Dairy Sci. 82:2259-2273.
Duffield, T. F., D. Sandals, K. E. Leslie, K. Lissemore, B. W. McBride, J. H. Lumsden, P. Dick, and R. Bagg. 1998a. Effect of prepartum administration of monensin in a controlled-release capsule on postpartum energy indicators in lactating dairy cows. J. Dairy Sci. 81:2354-2361.

Duffield, T. F., D. Sandals, K. E. Leslie, K. Lissemore, B. W. McBride, J. H. Lumsden, P. Dick, and R. Bagg. 1998b. Efficacy of monensin for the prevention of subclinical ketosis in lactating dairy cows. J. Dairy Sci. 81:2866-2873.

Dyk, P. B., R. S. Emery, J. L. Liesman, H. F. Bucholtz, and M. J. VandeHaar. 1995. Prepartum non-esterified fatty acids in plasma are higher in cows developing periparturient health problems. J. Dairy Sci. 78(Suppl. 1):264. (Abstr.)

Edmonson, A. J., I. J. Lean, L. D. Weaver, T. Farver, and G. Webster. 1989. A body condition scoring chart for Holstein dairy cows. J. Dairy Sci. 72:68-78.

Gerloff, B. 2001. Dairy cattle nutrition. Pages 476-471 in Herd Health: Food Animal Production Medicine. 3rd ed. O. M. Radostits, ed. W. B. Saunders, Philadelphia, PA.

Goff, J. P., and R. L. Horst. 1997. Physiological changes at parturition and their relationship to metabolic disorders. J. Dairy Sci. 80:1260-1268.

Green, B. L., B. W. McBride, D. Sandals, K. E. Leslie, R. Bagg, and P. Dick. 1999. The impact of a monensin controlled-release capsule on subclinical ketosis in the transition dairy cow. J. Dairy Sci. 82:333-342.

Grummer, R. R. 1995. Impact of changes in organic nutrient metabolism on feeding the transition dairy cow. J. Anim. Sci. 73:2820-2833.

Guidry, A. J., M. J. Paape, and R. E. Pearson. 1976. Effects of parturition and lactation on blood and milk cell concentrations, corticosteroids and neutrophil phagocytosis in the cow. Am. J. Vet. Res. 37:1195-1200.

Hayes, D. P., D. U. Pfeiffer, and N. B. Williamson. 1996. Effect of intraruminal monensin capsules on reproductive performance and milk production of dairy cows fed pasture. J. Dairy Sci. 79:1000-1008.

Hayirli, A., S. J. Bertics, and R. R. Grummer. 2002. Effects of slowrelease insulin on production, liver triglyceride, and metabolic profiles of Holsteins in early lactation. J. Dairy Sci. 85:2180-2191.

Herbein, J. H., R. J. Aiello, L. I. Eckler, R. E. Pearson, and R. M. Akers. 1985. Glucagon, insulin, growth hormone and glucose concentrations in plasma of lactating dairy cows. J. Dairy Sci. 68:320-325.

Heuer, C., Y. H. Schukken, L. J. Jonker, J. I. D. Wilkinson, and J. P. T. M. Noordhuizen. 2001. Effect of monensin on blood ketone bodies, incidence and recurrence of disease and fertility in dairy cows. J. Dairy Sci. 84:1085-1097.

Holtenius, K., S. Agenäs, C. Delavaud, and Y. Chilliard. 2003. Effects of feeding intensity during the dry period. 2. Metabolic and hormonal responses. J. Dairy Sci. 86:883-891.

Horst, R. L., and N. A. Jorgensen. 1982. Elevated plasma cortisol during induced and spontaneous hypocalcemia in ruminants. J. Dairy Sci. 65:2332-2337.

Marquardt, J. P., R. L. Horst, and N. A. Jorgensen. 1977. Effect of parity on dry matter intake at parturition in dairy cattle. J. Dairy Sci. 60:929-934.

Oba, M., and M. S. Allen. 2003. Dose-response effects of intraruminal infusion of propionate on feeding behavior of lactating cows in early or midlactation. J. Dairy Sci. 86:2922-2931.

Patel, O. V., T. Takahashi, N. Takenouchi, M. Hirako, N. Sasaki, and I. Domeki. 1996. Peripheral cortisol levels throughout gestation in the cow: Effect of stage of gestation and foetal number. Br. Vet. J. 152:425-432.

Plaizier, J. C., A. Martin, T. Duffield, R. Bagg, P. Dick, and B. W. McBride. 2000. Effect of a prepartum administration of monensin in a controlled-release capsule on apparent digestibilities and nitrogen utilization in transition dairy cows. J. Dairy Sci. 83:2918-2925.

Preisler, M. T., P. S. D. Weber, R. J. Tempelman, R. J. Erskine, H. Hunt, and J. L. Burton. 2000. Glucocorticoid receptor expression 
profiles in mononuclear leukocytes of periparturient Holstein cows. J. Dairy Sci. 83:38-47.

Richardson, L. F., A. P. Raun, E. L. Potter, C. O. Cooley, and R. P. Rathmacher. 1976. Effect of monensin on rumen fermentation in vitro and in vivo. J. Anim. Sci. 43:657-664.

Sauer, F. D., J. K. G. Kramer, and W. J. Cantwell. 1989. Antiketogenic effects of monensin in early lactation. J. Dairy Sci. 72:436-442.

Schwalm, J. W., and H. A. Tucker. 1978. Glucocorticoids in mammary secretions and blood serum during reproduction and lactation and distributions of glucocorticoids, progesterone and estrogens in fractions of milk. J. Dairy Sci. 61:550-560.

Sovani, S., C. Heuer, W. M. Van Straalen, and J. P. T. M. Noordhuizen. 2000 . Disease in high producing dairy cows following post parturient negative energy balance. Pages 33-50 in Soc. Vet. Epid. Prev. Med. Proc. Edinburgh, UK, March 29-31, 2000. Soc. Vet. Epidemiol. Prev. Med., UK.

Stephenson, K. A., I. J. Lean, M. L. Hyde, M. A. Curtis, J. K. Garvin, and L. B. Lowe. 1997. Effects of monensin on the metabolism of periparturient dairy cows. J. Dairy Sci. 80:830-837.

Thomas, E. E., S. E. Poe, R. K. McGuffey, D. H. Mowrey, and R. D. Allrich. 1993. Effect of feeding monensin to dairy cows on milk production and serum metabolites during early lactation. J. Dairy Sci. 76(Suppl. 1):280. (Abstr.)
Tucker, H. A. 2000. Hormones, mammary growth and lactation: A 41-year perspective. J. Dairy Sci. 83:874-884.

Tyler, J. W., D. F. Wolfe, and R. Maddox. 1992. Clinical indications for dietary ionophores in ruminants. Compend. Contin. Educ. Pract. Vet. 14:989-993.

Vallimont, J. E., G. A. Varga, A. Arieli, T. W. Cassidy, and K. A Cummins. 2001. Effects of prepartum somatotropin and monensin on metabolism and production of periparturient Holstein dairy cows. J. Dairy Sci. 84:2607-2621.

Van Winden, S. C. L., R. Jorritsma, K. E. Müller, and J. P. T. M. Noordhuizen. 2003. Feed intake, milk yield and metabolic parameters prior to left displaced abomasums in dairy cows. J. Dairy Sci. 86:1465-1471.

Vazquez-Anon, M., S. J. Bertics, M. Luck, and R. R. Grummer. 1994. Peripartum liver triglyceride and plasma metabolites. J. Dairy Sci. 77:1521-1528.

Wagner, J. R., H. B. Green, J. T. Symanowski, J. I. D. Wilkinson, J. S. Davis, M. R. Himstedt, M. S. Allen, E. Bock, J. J. Brennan, H. H. Head, J. J. Kenelly, J. N. Nielsen, J. E. Nocek, M. J. Van Der List, and L. W. Whitlow. 1999. Effect of monensin on feed intake, body weight, and body condition in dairy cows. J. Dairy Sci. 82(Suppl. 1):75. 